NASA/TM-2000-209958

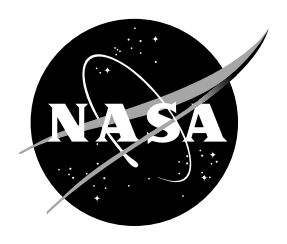

\title{
Surface Segregation in Ternary Alloys
}

Brian Good

Glenn Research Center, Cleveland, Ohio

Guillermo H. Bozzolo

Ohio Aerospace Institute, Cleveland, Ohio

Phillip B. Abel

Glenn Research Center, Cleveland, Ohio 
Since its founding, NASA has been dedicated to the advancement of aeronautics and space science. The NASA Scientific and Technical Information (STI) Program Office plays a key part in helping NASA maintain this important role.

The NASA STI Program Office is operated by Langley Research Center, the Lead Center for NASA's scientific and technical information. The NASA STI Program Office provides access to the NASA STI Database, the largest collection of aeronautical and space science STI in the world. The Program Office is also NASA's institutional mechanism for disseminating the results of its research and development activities. These results are published by NASA in the NASA STI Report Series, which includes the following report types:

- TECHNICAL PUBLICATION. Reports of completed research or a major significant phase of research that present the results of NASA programs and include extensive data or theoretical analysis. Includes compilations of significant scientific and technical data and information deemed to be of continuing reference value. NASA's counterpart of peerreviewed formal professional papers but has less stringent limitations on manuscript length and extent of graphic presentations.

- TECHNICAL MEMORANDUM. Scientific and technical findings that are preliminary or of specialized interest, e.g., quick release reports, working papers, and bibliographies that contain minimal annotation. Does not contain extensive analysis.

- CONTRACTOR REPORT. Scientific and technical findings by NASA-sponsored contractors and grantees.
- CONFERENCE PUBLICATION. Collected papers from scientific and technical conferences, symposia, seminars, or other meetings sponsored or cosponsored by NASA.

- SPECIAL PUBLICATION. Scientific, technical, or historical information from NASA programs, projects, and missions, often concerned with subjects having substantial public interest.

- TECHNICAL TRANSLATION. Englishlanguage translations of foreign scientific and technical material pertinent to NASA's mission.

Specialized services that complement the STI Program Office's diverse offerings include creating custom thesauri, building customized data bases, organizing and publishing research results ... even providing videos.

For more information about the NASA STI Program Office, see the following:

- Access the NASA STI Program Home Page at http://www.sti.nasa.gov

- E-mail your question via the Internet to help@sti.nasa.gov

- Fax your question to the NASA Access Help Desk at (301) 621-0134

- Telephone the NASA Access Help Desk at (301) 621-0390

- Write to:

NASA Access Help Desk

NASA Center for AeroSpace Information 7121 Standard Drive

Hanover, MD 21076 
NASA/TM-2000-209958

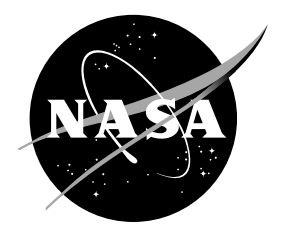

\section{Surface Segregation in Ternary Alloys}

\section{Brian Good}

Glenn Research Center, Cleveland, Ohio

Guillermo H. Bozzolo

Ohio Aerospace Institute, Cleveland, Ohio

Phillip B. Abel

Glenn Research Center, Cleveland, Ohio

National Aeronautics and

Space Administration

Glenn Research Center 


\section{Acknowledgments}

Fruitful discussions with N. Bozzolo are gratefully acknowledged. This work was funded by the HITEMP and PPM programs at NASA Glenn Research Center.

Available from

NASA Center for Aerospace Information 7121 Standard Drive

Hanover, MD 21076

Price Code: A03
National Technical Information Service 5285 Port Royal Road Springfield, VA 22100 Price Code: A03 


\title{
SURFACE SEGREGATION IN TERNARY ALLOYS
}

\author{
Brian Good \\ National Aeronautics and Space Administration \\ Glenn Research Center \\ Cleveland, Ohio 44135 \\ Guillermo H. Bozzolo \\ Ohio Aerospace Institute \\ Brook Park, Ohio 44142 \\ Phillip B. Abel \\ National Aeronautics and Space Administration \\ Glenn Research Center \\ Cleveland, Ohio 44135
}

\begin{abstract}
SUMMARY
Surface segregation profiles of binary $(\mathrm{Cu}-\mathrm{Ni}, \mathrm{Au}-\mathrm{Ni}, \mathrm{Cu}-\mathrm{Au})$ and ternary $(\mathrm{Cu}-\mathrm{Au}-\mathrm{Ni})$ alloys are determined via Monte Carlo-Metropolis computer simulations using the BFS method for alloys for the calculation of the energetics. The behavior of $\mathrm{Cu}$ or $\mathrm{Au}$ in $\mathrm{Ni}$ is contrasted with their behavior when both are present. The interaction between $\mathrm{Cu}$ and $\mathrm{Au}$ and its effect on the segregation profiles for $\mathrm{Cu}-\mathrm{Au}-\mathrm{Ni}$ alloys is discussed.
\end{abstract}

\section{INTRODUCTION}

Select binary systems have had their surface compositions thoroughly investigated both by experimental and by theoretical techniques, as reviewed in reference 1. Recent work also includes similar research for combinations of three or more elements (refs. 2 to 8), ranging from metal-semiconductor surfaces (ref. 9) to alloy impurity cosegregtion (refs. 10 and 11). The theoretical determination of temperature-dependent segregation profiles constitutes a severe test for any modeling effort, as it requires a great deal of accuracy from the model used in describing the simultaneous interactions of several atomic species. In this work, we present an extensive study of binary and ternary systems of $\mathrm{Ni}, \mathrm{Cu}$ and $\mathrm{Au}$ based on large-scale temperaturedependent Monte Carlo/Metropolis simulations using the Bozzolo-Ferrante-Smith (BFS) method for alloys (refs. 12 to 21) for computing the energy, and compare with experiment in those cases where data are available (refs. 22 to 26 ).

\section{THE BFS METHOD AND THE MONTE CARLO/METROPOLIS ALGORITHM}

Since its inception a few years ago, the BFS method has been applied to a variety of problems, ranging from bulk properties of solid solution fcc alloys (ref. 13) and the defect structure in ordered bcc alloys (refs. 14 and 15) to more specific applications including detailed studies of the structure and composition of alloy surfaces and surface alloys (ref. 16).

In what follows, we provide a brief description of the operational equations of BFS. The reader is encouraged to seek further details in previous papers where a detailed presentation of the foundation of the method, its basis in perturbation theory and a discussion of the approximations made are clearly shown (refs. 12 to 18).

The BFS method provides a simple algorithm for the calculation of the energy of formation of an arbitrary alloy (the difference between the energy of the alloy and that of its individual constituents). In BFS, the energy of formation $\Delta H$ is written as the superposition of elemental contributions $e_{i}$ of all the atoms in the alloy

$$
\Delta H=\sum_{i}\left(E_{i}^{\prime}-E_{i}\right)=\sum_{i} e_{i}
$$

where $E_{i}^{\prime}$ is the energy of atom $i$ in the alloy and $E_{i}$ is the corresponding value in a pure equilibrium monatomic crystal. In principle, the calculation of $\Delta H$ would simply imply computing the energy of each atom in its 
equilibrium pure crystal and then its energy in the alloy. In BFS, beyond directly computing the difference $e_{i}$ for each atom in the alloy, a two-step approach is introduced for such a calculation in order to identify contributions to the energy due to structural and compositional effects. Therefore, $e_{i}$ is broken up in two separate contributions: a strain energy $\left(e_{i}^{S}\right)$ and a chemical energy $\left(\varepsilon_{i}=e_{i}^{C}-e_{i}^{C_{0}}\right)$ While there is a certain level of arbitrariness in how this separation is implemented, it is only meaningful when a good representation of the actual process is obtained by properly linking both contributions. This is achieved by recoupling the strain and chemical contributions by means of a coupling function, $g_{i}$, properly defined to provide the correct asymptotic behavior of the individual components. Each individual contribution $e_{i}$ can therefore be written as

$$
e_{i}=e_{i}^{S}+g\left(e_{i}^{C}-e_{i}^{C_{0}}\right)
$$

The BFS strain energy contribution $e_{i}^{S}$ is defined as the contribution to the energy of formation from an atom in an alloy computed as if all the surrounding atoms were of the same atomic species, while maintaining the original structure of the alloy. To visualize this concept, figure 1(a) represents the atom in question (identified with an arrow) in an equilibrium position in its ground state crystal (arbitrarily represented by a simple cubic lattice). Figure 1(b) shows the same atom in the alloy being studied (also arbitrarily represented by a different crystallographic symmetry). Two things can be different between the reference crystal and the alloy. First, atoms of other species may occupy neighboring sites in the crystal and, second, the crystal lattice may not be equivalent in size or structure to that of the ground state crystal of the reference atom. In figure 1(b), the different atomic species are denoted with different symbols from that used for the reference atom, and the differences in size and/or structure are denoted with a schematically different atomic distribution as compared to the ground state crystal shown in figure 1(a). The BFS strain energy accounts for the change in energy due only to the change in geometrical environment of the crystal lattice (from figs. 1(a) to (b)), ignoring the additional degree of freedom introduced by the varying atomic species in the alloy. In this context, figure 1(c) shows the environment 'seen' by the reference atom when computing its BFS strain energy contribution. The neighboring atoms conserve the sites in the actual alloy (fig. 1(b)), but their chemical identity has changed to that of the reference atom (fig. 1(a)) thus simplifying the calculation to that of a single-element crystal. The BFS strain energy term represents the change in energy of the reference atom in going from the configuration denoted in figures 1(a) to (c). In this sense, the BFS strain energy differs from the commonly defined strain energy in that the actual chemical environment is replaced by that of a monatomic crystal. Its calculation is then straightforward, even amenable to first-principles techniques. In our work, we use Equivalent Crystal Theory (ECT) (refs. 19 and 20) for its computation, due to its proven ability to provide accurate and computationally economical answers to most general situations. In all cases considered in this work, a rigorous application of ECT is reduced to that of its two leading terms, which describe average density contributions and bond-compression anisotropies. We neglect the three- and four-body terms dealing with the bond angle and face-diagonal anisotropies.

The chemical environment of atom $i$ is considered in the computation of $e_{i}^{C}$, the first term in the total BFS chemical energy contribution, where the surrounding atoms maintain their identity but are forced to occupy equilibrium lattice sites corresponding to the reference atom $i$. Following the convention introduced in figures 1 and 2(a) shows the reference atom in the actual alloy (similar to fig. 1(b)), while figure 2(b) indicates the atomic distribution used in computing the BFS chemical energy $e_{i}^{C}$ (note that the lattice used in fig. 2(b) corresponds to that of the ground state crystal of the reference atom, as shown in fig. 1(a)). The total BFS chemical energy is then the difference between the energy of the reference atom in figure 2(b), $e_{i}^{C}$, and its energy in its ground state crystal (fig. 1(a)). Building on the concepts of ECT, a straightforward approach for the calculation of the chemical energy is defined, properly parameterizing the interaction between dissimilar atoms. The second contribution to the chemical energy $e_{i}^{C_{0}}$ (fig. 1(a)) is included in order to completely free the chemical energy from structural defects, taking into account the possibility that the reference atom is not in a full-coordination environment. This is accomplished by recomputing the contribution $e_{i}^{C}$ defined before, but once again assuming that all atoms are of the same species as the reference atom.

As mentioned above, the BFS strain and chemical energy contributions take into account different effects, i.e., geometry and composition, computing them as isolated effects. A coupling function, $g_{i}$, restores the relationship between the two terms. This factor is defined in such a way as to properly consider the asymptotic behavior of the chemical energy, where chemical effects are negligible for large separations between 
dissimilar atoms. Within the framework of this discussion, the total BFS contribution $e_{i}$ of each atom in the alloy can be graphically depicted by the combination of strain and chemical effects shown in figure 3 .

In what follows, we provide the basic operational equations needed to compute each one of the terms introduced above. The BFS strain energy contribution $e_{i}^{S}$ is obtained by solving the ECT perturbation equation

$$
N R_{1}^{p_{i}} e^{-\alpha_{i} R_{1}}+M R_{2}^{p_{i}} e^{-\left(\alpha_{i}+1 / \lambda_{i}\right) R_{2}}=\sum_{j} r_{j}^{p_{i}} e^{-\left(\alpha_{i}+S\left(r_{j}\right)\right) r_{j}}
$$

where $N$ and $M$ are the number of nearest- and next-nearest neighbors respectively, and where $p, l, \alpha$ and $\lambda$ are ECT parameters that describe element $i$ (see ref. 17 for definitions and details), $r$ denotes the distance between the reference atom and its neighbors, $S(r)$ describes a screening function (ref. 19) and the sum runs over nearest- and next-nearest neighbors. This equation determines the lattice parameter of a perfect equivalent crystal where the reference atom $i$ has the same energy as it has in the geometrical environment of the alloy under study. $R_{l}$ and $R_{2}$ denote the nearest- and next-nearest neighbor distances in this equivalent crystal.

Once the lattice parameter of the (strain) equivalent crystal, $a^{S}$, is determined, the BFS strain energy contribution is computed using the universal binding energy relation of Rose et al. (ref. 20), which contains all the relevant information concerning a single-component system:

$$
e_{i}^{S}=E_{C}^{i}\left(1-\left(1+a_{i}^{S^{*}}\right) e^{-a_{i}^{S^{*}}}\right)
$$

where $E_{C}^{i}$ is the cohesive energy of atom $i$ and where the scaled lattice parameter $a_{i}^{S^{*}}$ is given by

$$
a_{i}^{S^{*}}=q\left(a_{i}^{S}-a_{e}^{i}\right) / l_{i}
$$

where $q$ is the ratio between the equilibrium Wigner-Seitz radius and the equilibrium lattice parameter $a_{e}^{i}$.

The BFS chemical energy is obtained by a similar procedure. As opposed to the strain energy term, the surrounding atoms retain their chemical identity, but are forced to be in equilibrium lattice sites of an equilibrium (otherwise monatomic) crystal $i$. The BFS equation for the chemical energy is given by

$$
N R_{1}^{p_{i}} e^{-\alpha_{i} R_{1}}+M R_{2}^{p_{i}} e^{-\left(\alpha_{i}+1 / \lambda_{i}\right) R_{2}}=\sum_{k}\left(N_{i k} r_{1}^{p_{i}} e^{-\alpha_{i k} r_{k}}+M_{i k} r_{2}^{p_{i}} e^{-\left(\alpha_{i k}+1 / \lambda_{i}\right) r_{2}}\right)
$$

where $N_{i k}$ and $M_{i k}$ are the number of nearest- and next-nearest neighbors of species $k$ of atom $i$. The chemical environment surrounding atom $i$ is reflected in the parameters $\alpha_{i k}$, given by

$$
\alpha_{i k}=\alpha_{i}+\Delta_{k i}
$$

where the BFS parameters $\Delta$ (a perturbation on the single-element ECT parameter $\alpha_{\mathrm{i}}$ ) describe the changes of the wave function in the overlap region between atoms $i$ and $k$. Once equation (6) is solved for the equivalent chemical lattice parameter $a_{i}^{C}$, the BFS chemical energy is then

$$
\varepsilon_{i}^{C}=\gamma_{i} E_{C}^{i}\left(1-\left(1+a_{i}^{C^{*}}\right) e^{-a_{i}^{C^{*}}}\right)
$$

where $\gamma_{i}=1$ if $a_{i}^{C^{*}}>0$ and $\gamma_{i}=-1$ if $a_{i}^{C^{*}}<0$. The scaled chemical lattice parameter is given by

$$
a_{i}^{C^{*}}=q\left(a_{i}^{C}-a_{e}^{i}\right) / l_{i}
$$


Finally, as mentioned above, the BFS chemical and strain energy contributions are linked by a coupling function $g_{i}$ which describes the influence of the geometrical distribution of the surrounding atoms in relation to the chemical effects and is given by

$$
g_{i}=e^{-a_{i}^{S^{*}}}
$$

where the scaled lattice parameter $a_{i}^{S^{*}}$ is defined in equation (5).

In this work we used the BFS interaction parameters $\Delta$ determined following the procedure outlined in reference 13. The pure element parameters $a_{e}, E_{c}, l, \alpha, \lambda$ and the BFS parameters $\Delta_{P d C u}$ and $\Delta_{C u P d}$ used in this study are listed in Table I.

Large scale simulations were performed, covering a wide range of concentration for all the alloys considered, using the Monte Carlo-Metropolis algorithm and the BFS method for the calculation of the energetics. The temperature treatment is simulated by means of an algorithm where pairs of atoms of different species are allowed to switch places. The switch is accepted if it lowers the energy, or with probability $\exp (-\Delta \mathrm{E} / \mathrm{kT})$ otherwise, where $\mathrm{k}$ is Boltzman's constant, $\mathrm{T}$ is the temperature and $\Delta \mathrm{E}$ is the difference in energy of the cell before and after the switch. The changes in atomic distribution are allowed to continue until the total energy of the cell stabilizes.

\section{RESULTS AND DISCUSSION}

The segregation profiles for several $\mathrm{Cu}-\mathrm{Ni}, \mathrm{Cu}-\mathrm{Au}$ and $\mathrm{Au}-\mathrm{Ni}$ alloys were determined. The results for some selected concentrations for $\mathrm{Cu}-\mathrm{Ni}$ and $\mathrm{Au}-\mathrm{Ni}$ alloys are displayed in figure 1. While the Monte Carlo simulations include an appropriate temperature treatment for these alloys, there are restrictions in the calculation directed to simplify the numerical task to a reasonable level. Perhaps, the most important approximation relates to the use of a rigid lattice with a fixed lattice parameter throughout the computational cell, thus disallowing for multilayer or individual relaxations. In most cases, there is no experimental knowledge of the lattice parameters for the bulk ternary alloys. We therefore used approximate values based on the BF rule (ref. 21).

For $\mathrm{Cu}-\mathrm{Ni}$, it is observed that $\mathrm{Cu}$ always segregates to the surface plane, and to the second layer as well, as the $\mathrm{Cu}$ concentration $\left(\mathrm{x}_{\mathrm{Cu}}\right)$ increases. The surface concentration of $\mathrm{Cu}$ attains a maximum even for small values of bulk $\mathrm{Cu}$ concentration, in excellent agreement with experiment and other theoretical models (refs. 1 to 12, and 22). The monotonic profile characteristic of low $\mathrm{Cu}$ concentrations is broken for $\mathrm{x}_{\mathrm{Cu}} \sim 10$ percent, where small fluctuations in $\mathrm{Cu}$ and $\mathrm{Ni}$ concentration per plane become apparent, without any differences in the composition of the top surface planes. This behavior progresses to a relatively smooth profile, with less pronounced oscillations for $\mathrm{Cu}$-rich alloys. It should be noted, however, that the apparent oscillations in the profiles shown in figures 4(a) to (d) most likely represent fluctuations in concentration, highly dependent on the temperature treatment in the simulation, rather than actual oscillatory patterns. For Au-Ni, Au segregation to the surface plane is observed in all cases, in agreement with experiment (refs. 1 and 23), with the additional feature of clearly defined oscillations. While the abundance of Au in the surface has been found experimentally (ref. 22), no other theoretical or experimental evidence exist to support or contradict the behavior observed in figures $4(\mathrm{e})$ to $(\mathrm{h})$ for the first few planes immediately below the surface plane. $\mathrm{Cu}-\mathrm{Au}$ profiles show a small departure from the corresponding ordered bulk structure characteristic of these alloys beyond the top surface planes. It is observed that the surface plane is always rich in $\mathrm{Au}$, in agreement with experiment (refs. 24 and 25). In particular, the 1Cu-99Au case shown in figure 5(a) shows evidence of two competing segregation mechanisms, where $\mathrm{Au}$ populates the surface plane and $\mathrm{Cu}$ segregates to the plane immediately below the surface. This result is in agreement with the experimental finding of full occupancy of Au atoms in the first layer inducing the depletion of Au atoms in the layer below (refs. 24 to 26).

The successful comparison of the results for binary systems with available experimental data and, in particular, the examination of three substantially different behaviors for each of the three binary alloys studied, provides a solid foundation for extending the approach to model three-component systems. With the solid foundation developed with these examples, we now study the $\mathrm{Cu}-\mathrm{Au}-\mathrm{Ni}$ system and apply the same method-ology to determine the surface composition of a variety of $\mathrm{Cu}-\mathrm{Au}-\mathrm{Ni}$ alloys.

While both $\mathrm{Au}$ and $\mathrm{Cu}$ show a tendency to segregate to the outermost layers in $\mathrm{Au}-\mathrm{Ni}$ and $\mathrm{Cu}-\mathrm{Ni}$ alloys, the interaction between $\mathrm{Cu}$ and $\mathrm{Au}$ in $\mathrm{Cu}-\mathrm{Au}$ alloys indicates that the competition between $\mathrm{Cu}$ and $\mathrm{Au}$ in Ni-rich ternary systems, studied in figure 6, might not be anticipated from the behavior of binary systems alone. The profile shown in figure 6(a) indicates that, for the same (low) $\mathrm{Cu}$ and $\mathrm{Au}$ concentration, 
$\mathrm{Cu}$ segregates to the surface, as is the case when the concentration of $\mathrm{Cu}$ exceeds that of Au (figs. 6(a), (c), and (g)). Not surprisingly, even for small amounts of Au the tendency for Au surface segregation rapidly overcomes that of $\mathrm{Cu}$, to the point where there is a direct competition for populating the surface plane between the two components in $4 \mathrm{Cu}-1 \mathrm{Au}-95 \mathrm{Ni}$ (fig. 6(c)). For Au concentrations greater than 1 percent, the behavior of $\mathrm{Au}$ is dominant, inducing segregation patterns characteristic of Au-Ni or Au-Cu. As seen in figures 6(d), (e), and (g), $\mathrm{Cu}$ is lumped in the few layers below the Au-rich top layers. The best example of this behavior is seen in figure 6(d), where the first three layers have a population of Au and Ni similar to that seen in the binary case (fig. 5(b)), whereas $\mathrm{Cu}$ dominates the concentration pattern of the next few layers in a manner similar to that seen in figures 4(b) and (c). Another remarkable case corresponds to the $19 \mathrm{Cu}-1 \mathrm{Au}-80 \mathrm{Ni}$ where, with the exception of the top two layers, the concentration profile matches that seen for $20 \mathrm{Cu}-80 \mathrm{Ni}$ in figure 4 (d). However, the population of the top two layers is a clear demonstration of the competition between the surface segregation properties of $\mathrm{Cu}$ or $\mathrm{Au}$, yielding a mixed $\mathrm{Cu}-\mathrm{Au}$ surface plane. In summary, features that are characteristic of the binary systems $(\mathrm{Au}-\mathrm{Ni}, \mathrm{Cu}-\mathrm{Ni})$ directly compete in the ternary case, with slight modifications due to the interactions that arise between $\mathrm{Cu}$ and $\mathrm{Au}$ in the surface region.

\section{CONCLUSIONS}

The calculation of segregation profiles for binary and ternary alloys using Monte Carlo techniques and the BFS method for the energetics allows for a direct comparison between individual and collective behaviors of each one of the constituent elements. Due to the diverse behavior observed in the binary systems, the methodlogy was applied to the $\mathrm{Cu}-\mathrm{Au}-\mathrm{Ni}$ system for which no experimental data exists. The possibility of studying complex systems with such computational ease could provide a useful tool to assist in the development of experimental work on multicomponent systems.

\section{REFERENCES}

1. U. Bardi, Rep. Prog. Phys. 57 (1994) 939.

2. A. Landa, A. Ruban, P. Wynblatt, H. Skriver, A. Girshick, and V. Vitek, J. Phys.: Condens. Matter 10 (1998) 5717.

3. J.M. Moison, C. Guille, F. Houzay, F. Barthe, and M. Van Rompay, Phys. Rev. B 40 (1989) 6149.

4. F. Xu, C.M. Aldao, I.M. Vitomirov, Z. Lin, and J.H. Weaver, Phys. Rev. B 36 (1987) 3495.

5. N. Grandjean, J. Massies, and M. Leroux, Phys. Rev. B 53 (1996) 998.

6. G.P. Vyatkin, T.P. Privatova, S.I. Morozov, and A.E. Chudakov, Surf. Sci. (in press).

7. W. Schoenfeld, M. Pugalambers, B. Pathangey, D. Schoenfeld, and P.H. Holloway, Appl. Surf. Sci. 140 (1999) 204.

8. E. Clauberg, C. Uebing, H. Viefhaus, H.J. Grabke, Mat. Sci. Forum 294 (1999) 465.

9. Z. Lin, F. Xu, and J.H. Weaver, Phys. Rev. B 36 (1987) 5777.

10. T.T. Tsong, D.M. Ren, and M. Ahmad, Phys. Rev. B 38 (1988) 7428.

11. T. Muschik, S. Hofmann, W. Gust, and B. Predel, Appl. Surf. Sci. 37 (1989) 439.

12. G. Bozzolo, R.D. Noebe, J. Ferrante and C. Amador, J. Comput.-Aided Mater. Design 6 (1999) 1.

13. G. Bozzolo and J. Ferrante, J. Comput.-Aided Mater. Design 2 (1995) 13.

14. G. Bozzolo, J. Ferrante, R.D. Noebe, and C. Amador, Scripta Mater. 33 (1995) 1907.

15. G. Bozzolo, J. Ferrante, R.D. Noebe, and C. Amador, Scripta Mater. 36 (1997) 813.

16. G. Bozzolo, R. Ibanez-Meier, and J. Ferrante, Phys. Rev. B 51 (1995) 7207.

17. G. Bozzolo, R.D. Noebe, J. Ferrante, A. Garg, F. Honecy, and C. Amador, J. Comput.-Aided Mater. Design 6 (1999) 33.

18. G. Bozzolo, J. Ferrante, and A.M. Rodriguez, J. Comput.-Aided Mater. Design 1 (1993) 285.

19. J.R. Smith, T. Perry, A. Banerjea, J. Ferrante, and G. Bozzolo, Phys. Rev. B 44 (1991) 6444.

20. J.H. Rose, J.R. Smith, and J. Ferrante, Phys. Rev. B 28 (1983) 1835.

21. G. Bozzolo and J. Ferrante, Phys. Rev. B 50 (1994) 5971.

22. I. Dasgupta and A. Mookerjee, J. Phys.: Condens. Matter 8 (1996) 4125; B. Good, G. Bozzolo, and J. Ferrante, Phys. Rev. B 48 (1993) 18284, and references therein.

23. J.J. Burton, C.R. Helms, and R.S. Polizzotti, Surf. Sci. 57 (1976) 425.

24. S. Nakanishi, K. Kawamoto, N. Fukuoka, and K. Umezawa, Surf. Sci. 261 (1992) 342.

25. G.A. Eckstein, S. Maupai, A.S. Dakkouri, M. Stratmann, M. Nielsen, M.M. Nielsen, R. Feidenhans'l, J.H. Zeysing, O. Bunk, and R.L. Johnson, Phys. Rev. B 60 (1999) 8321.

26. H. Reichert, P. J. Eng, H. Dosch and I. K. Robinson, Phys. Rev. Lett. 74 (1995) 2006. 
TABLE I.-EXPERIMENTAL RESULTS USED FOR THE DETERMINATION OF THE

ECT AND BFS PARAMETERS ${ }^{\mathrm{a}}$

\begin{tabular}{|c|c|c|c|c|c|c|c|}
\hline & \multicolumn{3}{|c|}{ Experimental results } & & \multicolumn{3}{|c|}{ ECT paramters } \\
\hline & $\begin{array}{c}\text { Latice param- } \\
\text { ter, } \\
\AA\end{array}$ & $\begin{array}{c}\text { Cohesive en- } \\
\text { ergy, } \\
\text { eV }\end{array}$ & $\begin{array}{l}\text { Bulk modulus, } \\
\text { GPa }\end{array}$ & $\mathrm{p}$ & $\left(\begin{array}{c}\alpha \\
\left(\AA^{-1}\right)\end{array}\right.$ & $\begin{array}{c}\lambda \\
\left(\AA^{-1}\right)\end{array}$ & $\begin{array}{c}1 \\
(\AA)\end{array}$ \\
\hline $\mathrm{Pd}$ & 3.890 & 3.94 & 195.77 & 8 & 3.612 & 0.666 & 0.237 \\
\hline $\mathrm{Cu}$ & 3.615 & 3.50 & 142.08 & 6 & 2.935 & 0.765 & 0.272 \\
\hline \multicolumn{8}{|c|}{ BFS parameters } \\
\hline
\end{tabular}

${ }^{a}$ The last four columns display the resulting equivalent crystal theory (ECT) (ref. 26) parameters: $p$ is related to the principal quantum umber $n$ for the atomic species considered $(p=2 n-2), \alpha$ parameterizes the electron density in the overlap region between two neighboring atoms, $\lambda$ is a screening factor for atoms at distances greater than nearestneighbor distance and $l$ is a scaling length needed to fit the lattice parameter dependence of the energy of formation with the universal binding energy relationship of Rose et al. (ref. 27). The last row displays the BFS parameters $\Delta_{\text {pdcu }}$ and $\Delta_{\text {cupd }}$ used in this work.

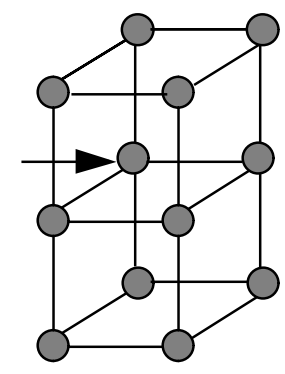

(a)

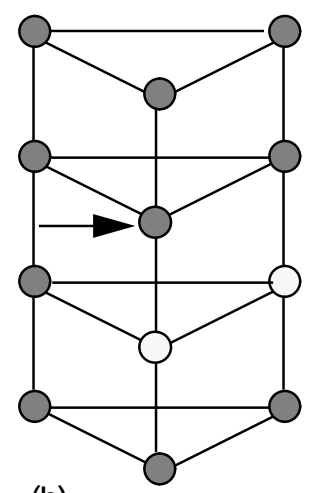

(b)

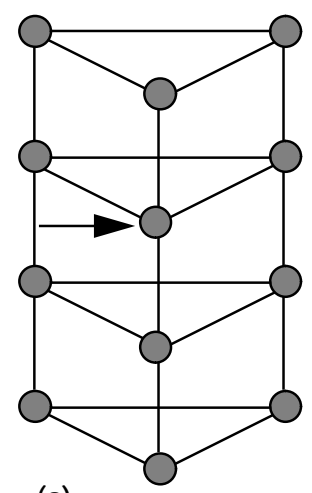

(c)

Figure 1.- (a) A pure, equilibrium crystal (reference atom denoted by the arrow), (b) a reference atom (denoted by the arrow) in the alloy to be studied (atoms of other species denoted with other shading) and (c) the same reference atom in a monatomic crystal, with the identical structure of the alloy to be studied, but with all the atoms of the same atomic species as the reference atom, for the calculation of the strain energy term for the reference atom. The strain energy is the differencein energy of the reference atom between (c) and (a). 

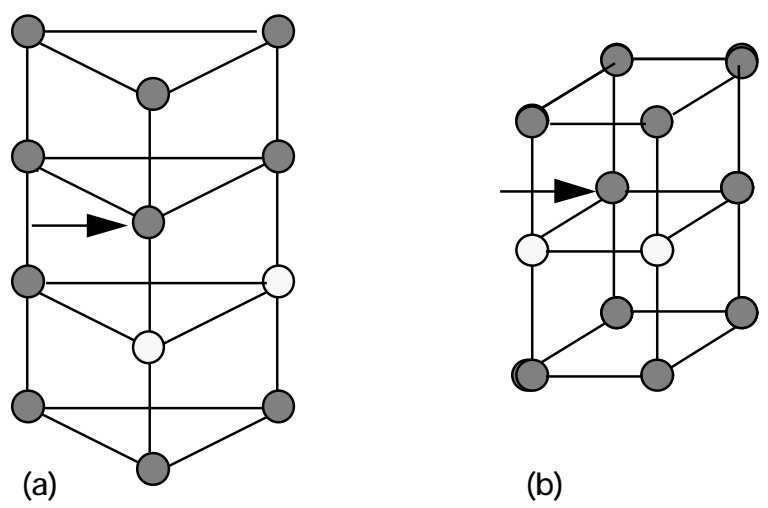

(b)

Figure 2.- (a) The reference atom (denoted by the arrow) in the actual alloy environment and (b) the reference atom surrounded by a chemical environment equivalent equivalent to that in (a) but with the different neighboring atoms occupying equilibrium lattice sites corresponding to the ground state of the reference atom.
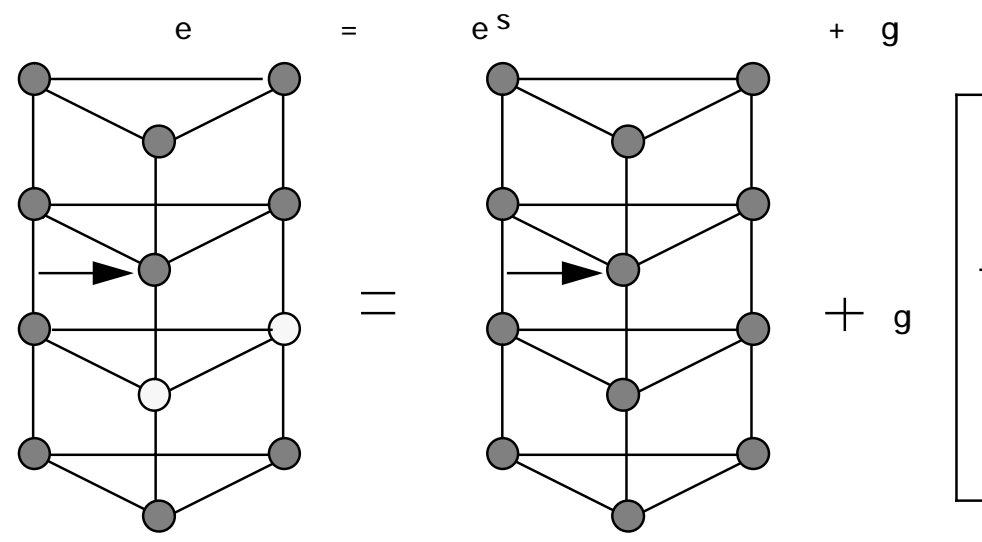

$$
\left(e^{\mathrm{C}}\right.
$$

$$
\left.-e^{c_{0}}\right)
$$
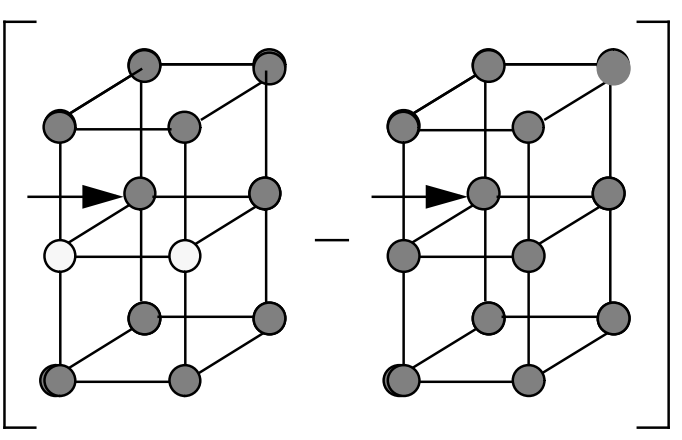

Figure 3.-Schematic representation of the BFS contributions to the total energy of formation. The left hand side represents the reference atom (denoted by an arrow) in an alloy. The different terms on the right hand side indicate the strain energy (atoms in their actual positions but of the same atomic species as the reference atom), the chemical energy term (atoms in ideal lattice sites) and the reference chemical energy (same as before, but with the atoms retaining the original identity of the reference atoms). 

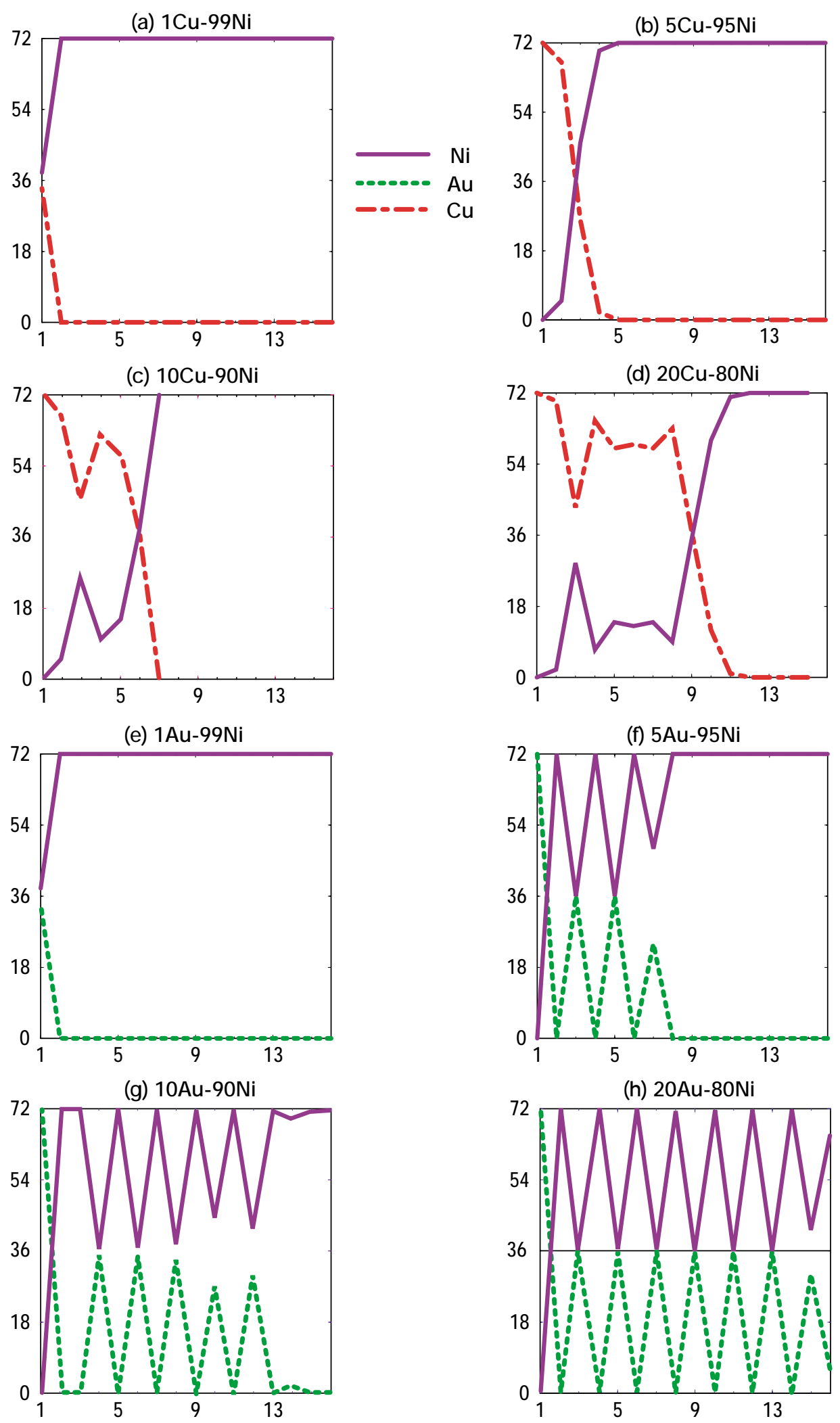

Figure 4.- Segregation profiles of $x C u-y N i(a-d)$ and $x A u-y N i(e-h)$ for $(x, y)=(1,99),(5,95),(10,90)$, and $(20,80)$. The horizontal axis indicates the atomic planes with the first one corresponds to the surface plane. The vertical axis denotes the population of each 72-atom plane. The purple solid line corresponds to Ni while the green dash line corresponds to $\mathrm{Au}(\mathrm{e}-\mathrm{h})$ and the red dot-dash line to $\mathrm{Cu}(\mathrm{a}-\mathrm{d})$. 
(a) 1C u-99Au

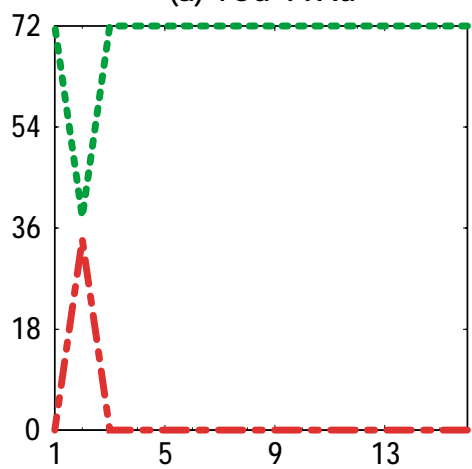

(c) $25 \mathrm{Cu}-75 \mathrm{Au}$

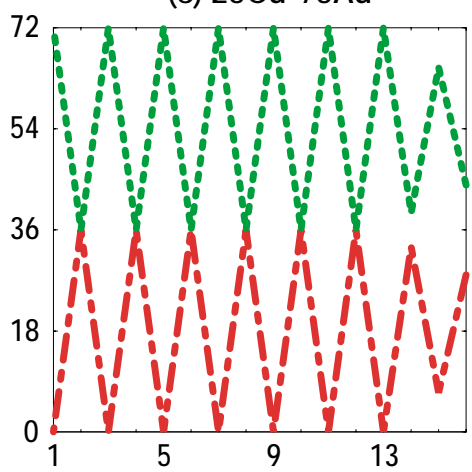

(e) $75 \mathrm{Cu}-25 \mathrm{Au}$

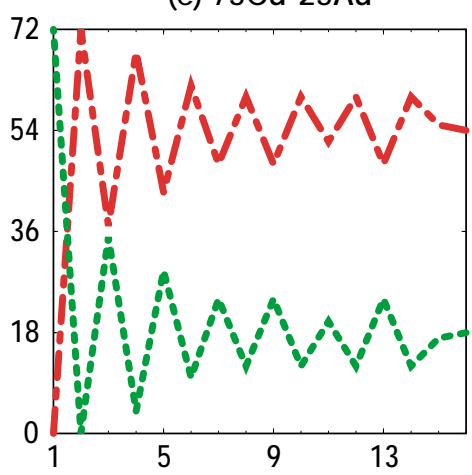

(b) 5C u-95Au

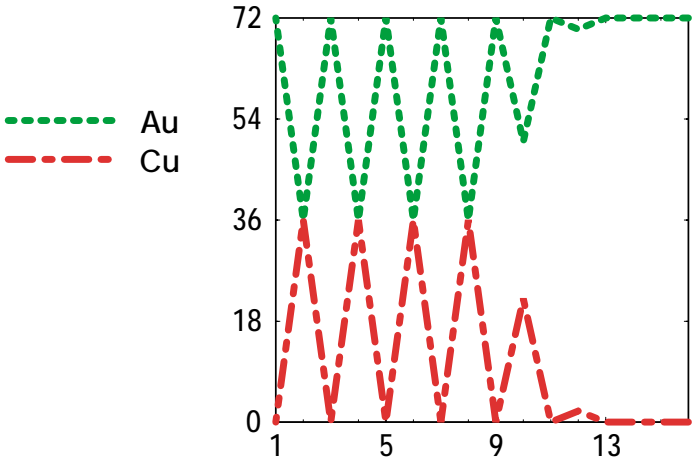

(d) $50 \mathrm{Cu}-50 \mathrm{Au}$

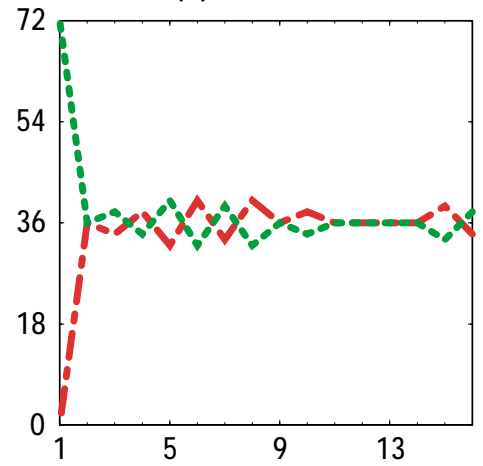

(f) $95 \mathrm{Cu}-5 \mathrm{Au}$

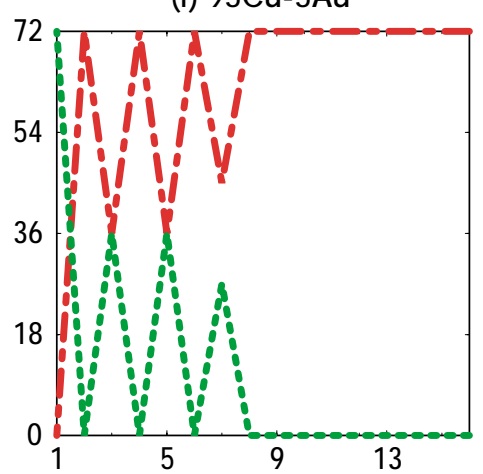

(g) $99 \mathrm{Cu}-1 \mathrm{Au}$

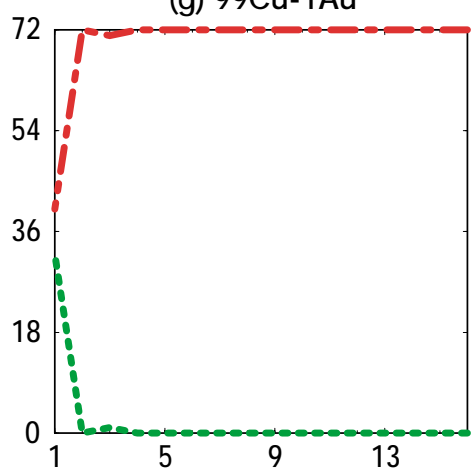

Figure 5. - (a-g) Segregation profiles of $x C u-y A u$ for $(x, y)=(1,99),(5,95),(25,75),(50,50)$, $(75,25),(95,5)$ and $(99,1)$. The horizontal axis indicates the atomic planes with the first one corresponds to the surface plane. The vertical axis denotes the population of each 72-atom plane. The green dash line corresponds to $\mathrm{Au}$ and the red dot-dash line to $\mathrm{Cu}$. 
(a) 1Cu-1Au-98Ni

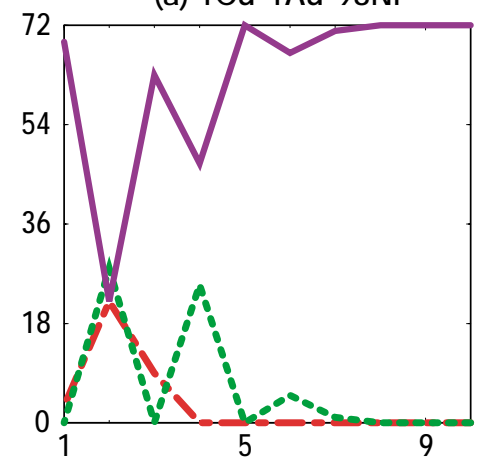

(c) 4 C u-1Au-95Ni

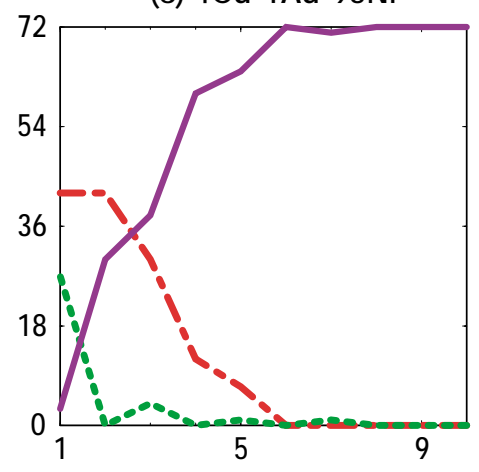

(e) $10 \mathrm{Cu}-10 \mathrm{Au}-80 \mathrm{Ni}$

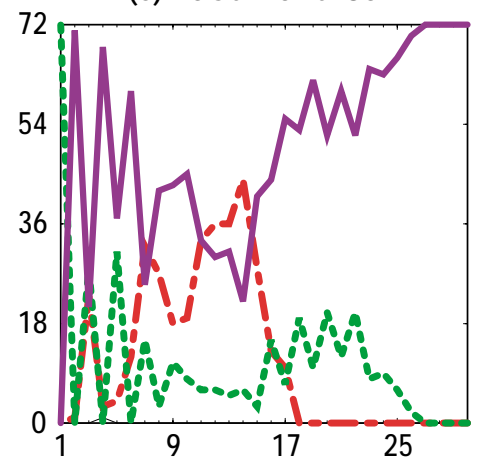

(g) $19 \mathrm{Cu}-1 \mathrm{Au}-80 \mathrm{Ni}$

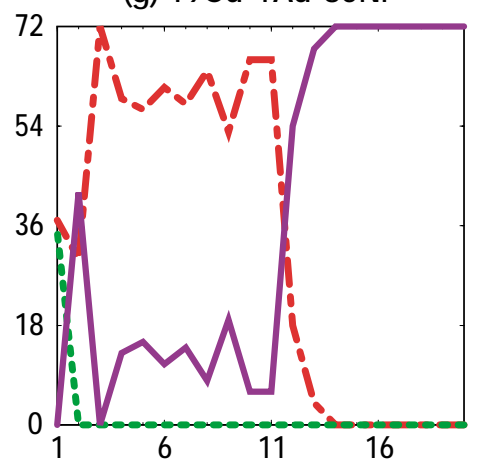

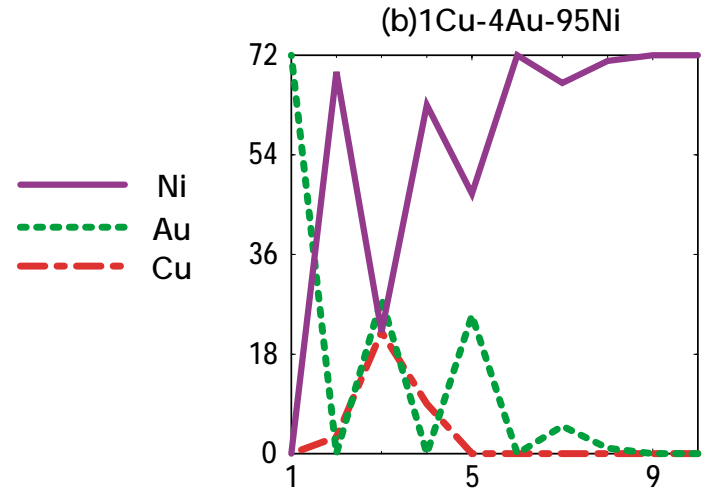

(d) 5Cu-5Au-90Ni
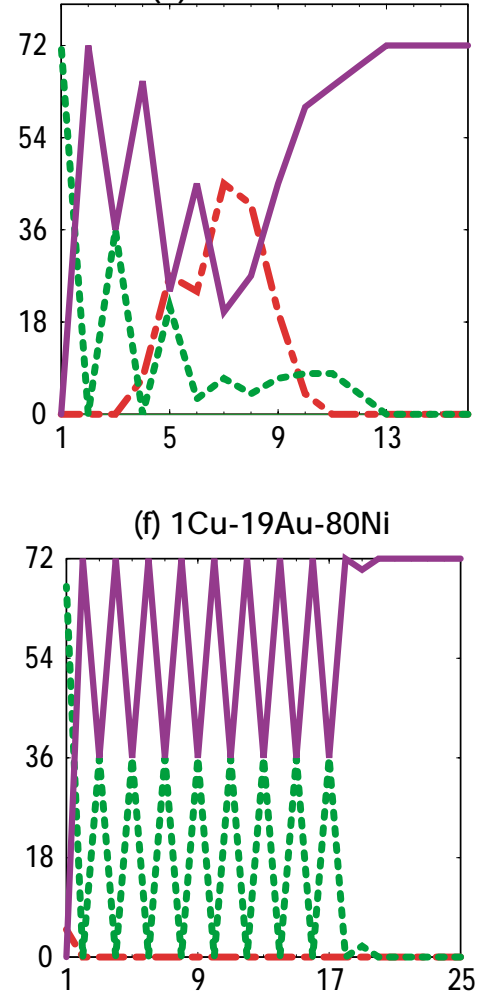

Figure 6. - Segregation profiles of (a-e) xC $u-y A u$ for $(x, y)=(1,1,98),(1,4,95),(4,1,95)$, $(5,5,90),(10,10,80),(1,19,80)$, and $(19,1,80)$. The horizontal axis is labeled by the number of planes. The vertical axis denotes the population of each 72-atom plane. The purple solid line corresponds to $\mathrm{Ni}$, the green dash line to $\mathrm{Au}$, and red dot-dash line to $\mathrm{Cu}$. 


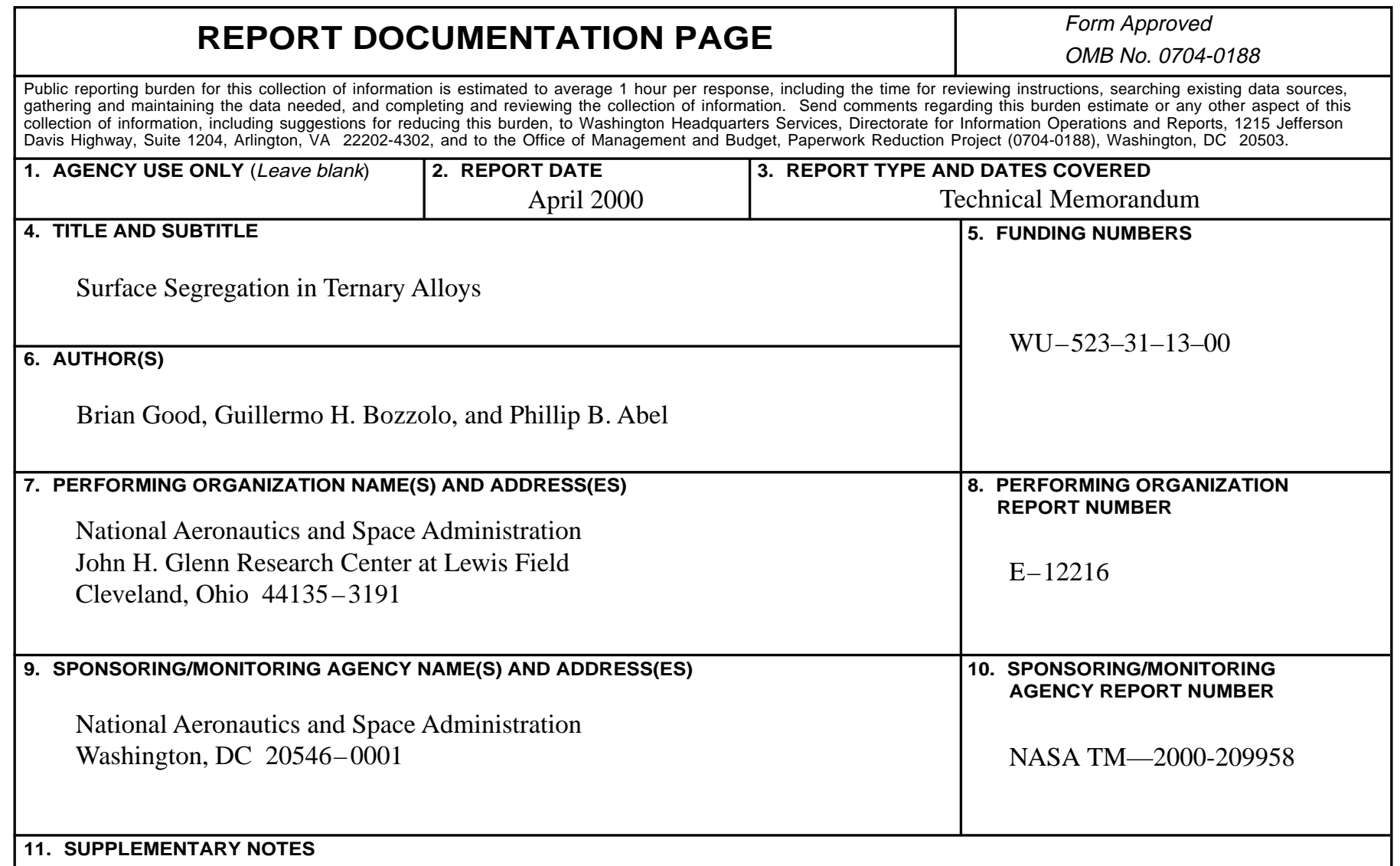

Brian Good and Phillip B. Abel, NASA Glenn Research Center, and Guillermo H. Bozzolo, Ohio Aerospace Institute, 22800 Cedar Point Road, Cleveland, Ohio 44142. Responsible person, Brian Good, organization code 5410, (216) 433-6296.

\begin{tabular}{|l|l|}
\hline 12a. DISTRIBUTION/AVAILABILITY STATEMENT & 12b. DISTRIBUTION CODE
\end{tabular}

Unclassified - Unlimited

Subject Categories: 26, 76, and $77 \quad$ Distribution: Nonstandard

This publication is available from the NASA Center for AeroSpace Information, (301) 621-0390.

\section{ABSTRACT (Maximum 200 words)}

Surface segregation profiles of binary $(\mathrm{Cu}-\mathrm{Ni}, \mathrm{Au}-\mathrm{Ni}, \mathrm{Cu}-\mathrm{Au})$ and ternary $(\mathrm{Cu}-\mathrm{Au}-\mathrm{Ni})$ alloys are determined via $\mathrm{Monte}$ Carlo-Metropolis computer simulations using the BFS method for alloys for the calculation of the energetics. The behavior of $\mathrm{Cu}$ or $\mathrm{Au}$ in $\mathrm{Ni}$ is contrasted with their behavior when both are present. The interaction between $\mathrm{Cu}$ and $\mathrm{Au}$ and its effect on the segregation profiles for $\mathrm{Cu}-\mathrm{Au}-\mathrm{Ni}$ alloys is discussed.

\begin{tabular}{|c|c|c|}
\hline \multicolumn{3}{|c|}{$\begin{array}{l}\text { Semiempirical methods; Segregation; Copper; Gold; Nickel; Computer simulations; } \\
\text { Surface segregation; Surface diffusion; Ternary alloys }\end{array}$} \\
\hline $\begin{array}{l}\text { 17. SECURITY CLASSIFICATION } \\
\text { OF REPORT } \\
\text { Unclassified }\end{array}$ & $\begin{array}{l}\text { 18. SECURITY CLASSIFICATION } \\
\text { OF THIS PAGE }\end{array}$ & $\begin{array}{l}\text { 19. SECURITY CLASSIFICATION } \\
\text { OF ABSTRACT }\end{array}$ \\
\hline Unclassified & Unclassified & Unclassified \\
\hline
\end{tabular}

15. NUMBER OF PAGES

16

16. PRICE CODE

A03

20. LIMITATION OF ABSTRACT

Standard Form 298 (Rev. 2-89)

Prescribed by ANSI Std. Z39-18 298-102 